\title{
Article \\ One-Step Preparation of Biochar Electrodes and Their Applications in Sediment Microbial Electrochemical Systems
}

\author{
Kui You, Zihan Zhou, Chao Gao and Qiao Yang *(D) \\ School of Ocean Science and Technology, Dalian University of Technology, No. 2 Dagong Road, \\ Liaodongwan District, Panjin 124221, China; ykmch@dlut.edu.cn (K.Y.); zzh529@mail.dlut.edu.cn (Z.Z.); \\ gaochao7755@163.com (C.G.) \\ * Correspondence: yangqiao@dlut.edu.cn; Tel.: +86-427-2631787
}

Citation: You, K.; Zhou, Z.; Gao, C.; Yang, Q. One-Step Preparation of Biochar Electrodes and Their Applications in Sediment Microbial Electrochemical Systems. Catalysts 2021, 11, 508. https://doi.org/ $10.3390 /$ catal11040508

Academic Editors: Vincenzo Baglio and David Sebastián

Received: 31 March 2021

Accepted: 15 April 2021

Published: 17 April 2021

Publisher's Note: MDPI stays neutral with regard to jurisdictional claims in published maps and institutional affiliations.

Copyright: (C) 2021 by the authors. Licensee MDPI, Basel, Switzerland. This article is an open access article distributed under the terms and conditions of the Creative Commons Attribution (CC BY) license (https:/ / creativecommons.org/licenses/by/ $4.0 /)$.
Abstract: Biochar is a kind of carbon-rich material formed by pyrolysis of biomass at high temperature in the absence or limitation of oxygen. It has abundant pore structure and a large surface area, which could be considered the beneficial characteristics for electrodes of microbial electrochemical systems. In this study, reed was used as the raw material of biochar and six biochar-based electrode materials were obtained by three methods, including one-step biochar cathodes (BC 800 and BC 700), biochar/polyethylene composite cathodes (BP 5:5 and BP 6:4), and biochar/polyaniline/hotmelt adhesive composite cathode (BPP 5:1:4 and BPP 4:1:5). The basic physical properties and electrochemical properties of the self-made biochar electrode materials were characterized. Selected biochar-based electrode materials were used as the cathode of sediment microbial electrochemical reactors. The reactor with pure biochar electrode (BC 800) achieves a maximum output power density of $9.15 \pm 0.02 \mathrm{~mW} / \mathrm{m}^{2}$, which increases the output power by nearly $80 \%$ compared with carbon felt. When using a biochar/polyaniline/hot-melt adhesive (BPP 5:1:4) composite cathode, the output power was increased by 2.33 times. Under the premise of ensuring the molding of the material, the higher the content of biochar, the better the electrochemical performance of the electrodes. The treatment of reed powder before pyrolysis is an important factor for the molding of biochar. The onestep molding biochar cathode had satisfactory performance in sediment microbial electrochemical systems. By exploring the biochar-based electrode, waste biomass could be reused, which is beneficial for the environment.

Keywords: microbial electrochemical systems; biochar; electrode material; power density; electricity generation

\section{Introduction}

Microbial electrochemical systems (MESs) have drawn increasing attention as a method that can simultaneously produce electricity and treat wastewater. Cathode materials have a direct impact on the performance of MESs. They should have high oxidationreduction potential to easily capture electrons. It is important to study the cathode materials of MESs. At present, common cathode materials include graphite, carbon cloth, and carbon paper. In order to improve the performance of the materials, high active catalysts can be used to modify the cathode to reduce the activation energy and improve the reaction rate. $\mathrm{Pt}$ is the most commonly used catalyst. The power density of MESs with Pt-containing graphite felt as a cathode can reach $150 \mathrm{~mW} / \mathrm{m}^{2}$ [1], which is three times that of a pure graphite cathode [2]. However, $\mathrm{Pt}$ is an expensive metal, which limits its practical application. In addition, the performance of MESs can be improved by increasing the surface area of the electrode. In the reactor systems with two-dimensional electrodes, changing the size of the electrode will generally lead to the increase of reactor volume and infrastructure cost. Using cheap three-dimensional electrodes to fill the reactor chamber can provide an effective solution for this problem. 
Three-dimensional electrodes can increase the attachment point of bacteria and the power density of the reactors. In theory, this should lead to better performance of the MESs. The commonly used filling materials are graphite granules (GGS) [3] and granuleactivated carbon (GAC) [4]. Exploring better three-dimensional electrode materials and their structure is still the key to improving the performance of MESs. Biochar is a kind of carbon-rich material formed by pyrolysis of biomass at high temperature in the absence or limitation of oxygen [5]. Common preparation methods of biochar include slow pyrolysis, hydrothermal carbonization, and high-temperature gasification. The sources of raw materials for biochar preparation are very wide [6,7]. The products made from different raw materials are also different. For example, the materials made from grasses are mostly liquid biofuels [8]. Biochar has been widely studied in environmental remediation because of its wide sources, low cost, and recyclability, including as energy substitute products, improving soil environment [9], transforming into activated carbon [10], and as an adsorbent [11,12]. In some studies, biochar and modified biochar materials have obtained good results in the adsorption of dyes and heavy metals $[13,14]$. Compared with GGS and GAC, biochar is a more cost-competitive option. In addition, biochar is also used as sensing materials. Analytical performances for biochar-based sensors are often reported as comparable to those of the best carbon-based sensing platforms [15]. Incorporating photocatalytic nanoparticles with biochar templates can produce biochar-supported photocatalysts [16]. In recent years, the preparation of electrodes by biochar has attracted some attention. Biochar electrodes exhibited voltametric responses similar to those of activated carbon under similar conditions [17]. Therefore, they are applied to supercapacitors [18] and microbial fuel cells [19-21]. The application of biochar in lithium secondary battery is summarized [22]. Research showed that the inherent macro-structure of biochar plays a significant role in determining the performance of monolithic biochar electrodes [23]. Some researchers have studied the modified electrodes based on biochar, but the biochar was used as a catalyst or catalyst carrier, and the biochar-relevant electrode was prepared by multiple steps $[24,25]$. In most earlier studies, only woody plants were used to prepare one-step molding biochar electrodes [26]. Compared with woody plants which have many other valuable applications, reed is a kind of common and easy to collect plant. In this study, reed will be used as the raw material of biochar, and we aim to develop a molding method for biochar electrodes. The influence of different pyrolysis temperatures on the properties of the products and the materials' properties prepared by different preparation methods will be studied.

\section{Results and Discussion}

\subsection{Analysis of the Biochar Materials}

It is important to treat reed powder with a suitable sieve for the molding of biochar electrodes. Otherwise, cracks easily form on the surface of biochar, as shown in Figure 4. As the biochar electrode precursor, the main components of reed stalk were hemicellulose, lignin, and cellulose. During the process of pyrolysis, the cellulose, hemicellulose, and lignin were decomposed $[27,28]$. The weight loss of hemicellulose and cellulose during pyrolysis mainly happened below 400 degrees, while lignin was more difficult to decompose and its weight loss happened from 160 to 900 degrees and then generated solid residue [29]. Biochar yield in this research is shown in Table 1, which was obtained by dividing the biochar production mass by the initial reed mass $(5 \mathrm{~g})$ in the corundum mold. With increasing pyrolysis temperature from 400 to $800{ }^{\circ} \mathrm{C}$, the yield decreased from $35.4 \%$ to $25.1 \%$. The specific surface area (SSA) of reed biochar can reach $68.53 \mathrm{~m}^{2} / \mathrm{g}$ when the pyrolysis temperature increases to $500{ }^{\circ} \mathrm{C}$ [30]. With increasing pyrolysis temperature from low temperature to $700{ }^{\circ} \mathrm{C}$, the SSA of biochar will be greatly advanced. Generally, the increase in surface area at high carbonization temperature is due to the removal of volatile material, resulting in increased micropore volume [31]. Meanwhile, densification of the carbon skeleton is improved. Insufficient carbonization at $600^{\circ} \mathrm{C}$ or excessive densification of the carbon skeleton at $1000{ }^{\circ} \mathrm{C}$ leads to the lower specific surface area or only macropores 
remain. The biochar pyrolyzed at $800{ }^{\circ} \mathrm{C}$ thus shows the optimal pore structure [32]. The size of biochar production was smaller than the initial mold size, and it could maintain a solid form and work as a piece of electrode. However, the resistances were too high for BC 400, BC 500, and BC 600 (Table 1). BC 700 and BC 800 had much lower resistances, and they were selected as the electrode samples (30-50 $\Omega$ for BC 800 and 300-500 $\Omega$ for $\mathrm{BC} 700$ ). The dimensions of the electrode $\mathrm{BC} 800$ were $50.0 \times 25.0 \times 3.8 \mathrm{~mm}$, and for $\mathrm{BC}$ 700 were $50.0 \times 25.0 \times 4.0 \mathrm{~mm}$. In this preparation method, sieving is a crucial step. If reed powder was not sieved as described, biochar could not be molded. In order to obtain better performance of the electrode, binder and conductive substance were mixed with the powder of BC 700 and pyrolysis was carried out again. BP (biochar powder mixed with polyethylene) and BPP (biochar powder mixed with polyaniline and hot-melt adhesive) with different mass ratios were obtained as the procedures mentioned above. All these six electrode samples had a similar size and could maintain a complete electrode shape in the reactors during this research. The prepared electrodes are shown in Figure 4.

Table 1. Biochar size and yield.

\begin{tabular}{cccc}
\hline $\begin{array}{c}\text { Heating } \\
\text { Temperature }\left({ }^{\circ} \mathbf{C}\right)\end{array}$ & $\begin{array}{c}\text { Size }(\mathbf{L} \times \mathbf{W} \times \mathbf{H}, \\
\pm \mathbf{0 . 1} \mathbf{~ m m})\end{array}$ & Resistance & Biochar Yield (\%) \\
\hline 400 & $54.0 \times 27.0 \times 4.3$ & Overload & 35.4 \\
500 & $52.0 \times 26.0 \times 4.2$ & $3.5-30 \mathrm{M} \Omega$ & 29.6 \\
600 & $51.0 \times 26.0 \times 4.1$ & $400-1400 \Omega$ & 28.0 \\
700 & $50.0 \times 25.0 \times 4.0$ & $300-500 \Omega$ & 27.2 \\
800 & $50.0 \times 25.0 \times 3.8$ & $30-50 \Omega$ & 25.1 \\
\hline
\end{tabular}

The Scanning electron microscope (SEM) of six biochar-based electrode materials are shown in Figure 1. The degradation and destruction of cellulose and lignin results in the formation of amorphous carbon structure and micropores [33]. As shown in Figure 1A,B, the surfaces of BC 800 and BC 700 were uneven, and the biochar was basically composed of cellular porous structure. The porous structure could provide a relatively large contact area with oxygen, which makes it possible to be used as cathode materials in MESs. Solid residue of lignin in $B C 700$ and $B C 800$ had a rough surface. Compared with the pure biochar BC 700, polyethylene was added in BP 5:5 and BP 6:4 with different mass ratios, and some lumpy objects could be observed in Figure 1C,D. BC 700 powder could be dispersed in polyethylene, and the polyethylene combined the biochar together acted as binders. X-ray diffraction (XRD) and Fourier transform infrared spectroscopy (FTIR) analysis of previous studies shows that the addition of biochar could make a change of intensity in the BP composites but had little effect on the crystalline structure [34]. There were no chemical reactions between biochar and high-density polyethylene (HDPE) [35]. The porous structure and large surface area of biochar allow polyethylene to flow inside the pores, and an interlocking developed due to which the composite can efficiently transfer stress [34]. With the addition of polyethylene, the compressive and torsional properties of the materials could be better, but the electrical conductivity of the materials was reduced. Polyaniline has good electrochemical properties, and it was added in BPP 5:1:4 and BPP 4:1:5. Compared with BC and BP, some attached particles on the surface of the biochar solid could be observed in Figure 1E,F. The polyethylene and polyaniline only modified the surface of biochar. Polyaniline was dispersed on the surface of the biochar bundle, which increased the conductivity of the composite. The actual electrochemical performance of the six kinds of biochar-based electrodes will be tested in the following research. 

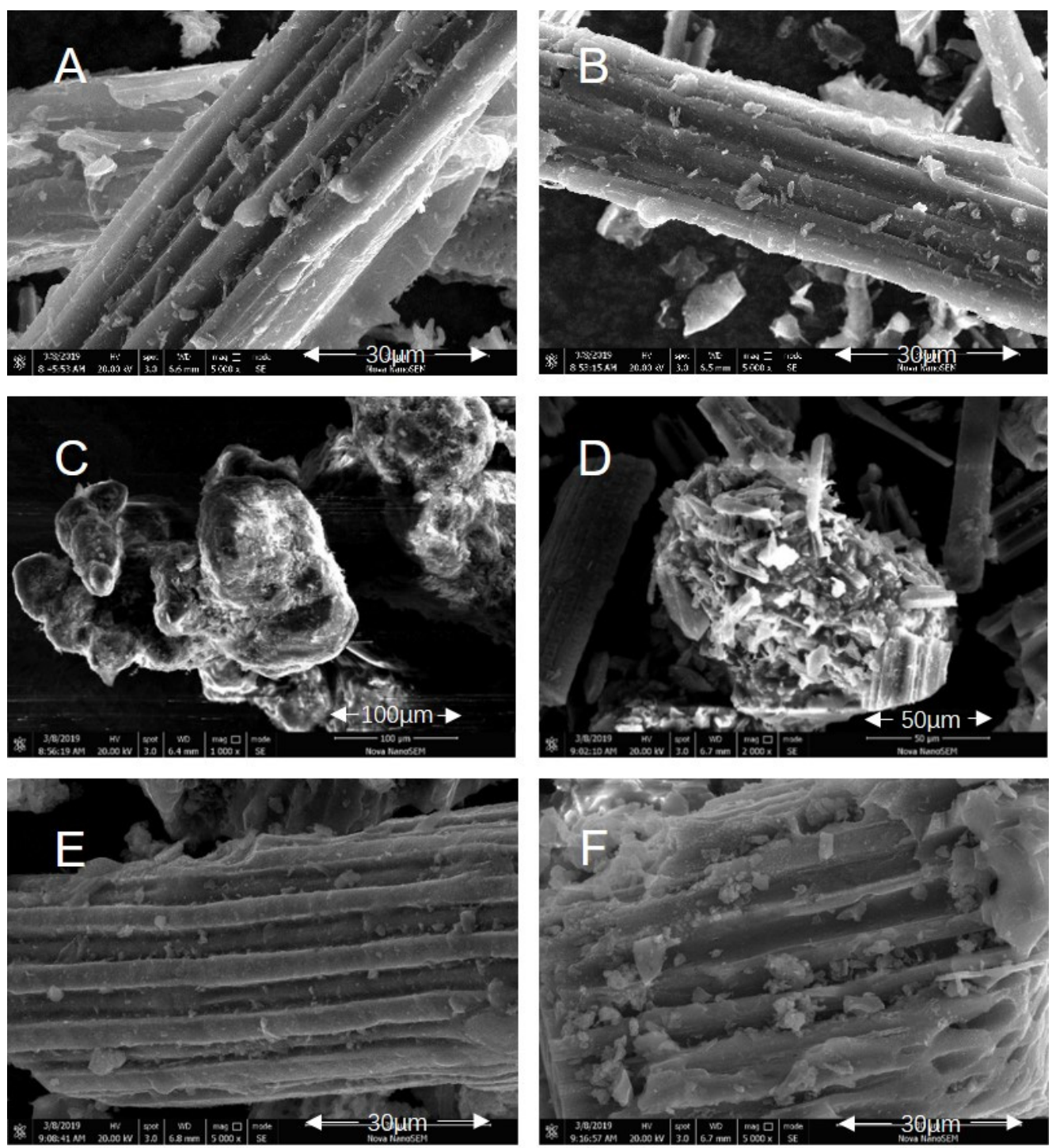

Figure 1. Scanning electron microscope images of (A) BC 800, (B) BC 700, (C) BP 5:5, (D) BP 6:4, (E) BPP 5:1:4, (F) BPP 4:1:5.

\subsection{Analysis of Electrochemical Properties of Biochar-Based Electrode}

The Linear sweep voltammetry (LSV) curves of six electrode materials are shown in Figure 2A. When the electric potential was scanned from 200 to $0 \mathrm{mV}$ (relative to $\mathrm{Ag} / \mathrm{AgCl}$ ), the current reached the maximum value. At the same potential, the current value of $\mathrm{BC}$ 800 was significantly higher than BC 700, which showed that BC 800 has better catalysis activity. Compared with $\mathrm{BC} 800$ and $\mathrm{BC} 700$, the curve trends of the other four electrode materials were not obvious in Figure 2A, which showed that BC 800 and BC 700 may be more suitable for electrode materials. 

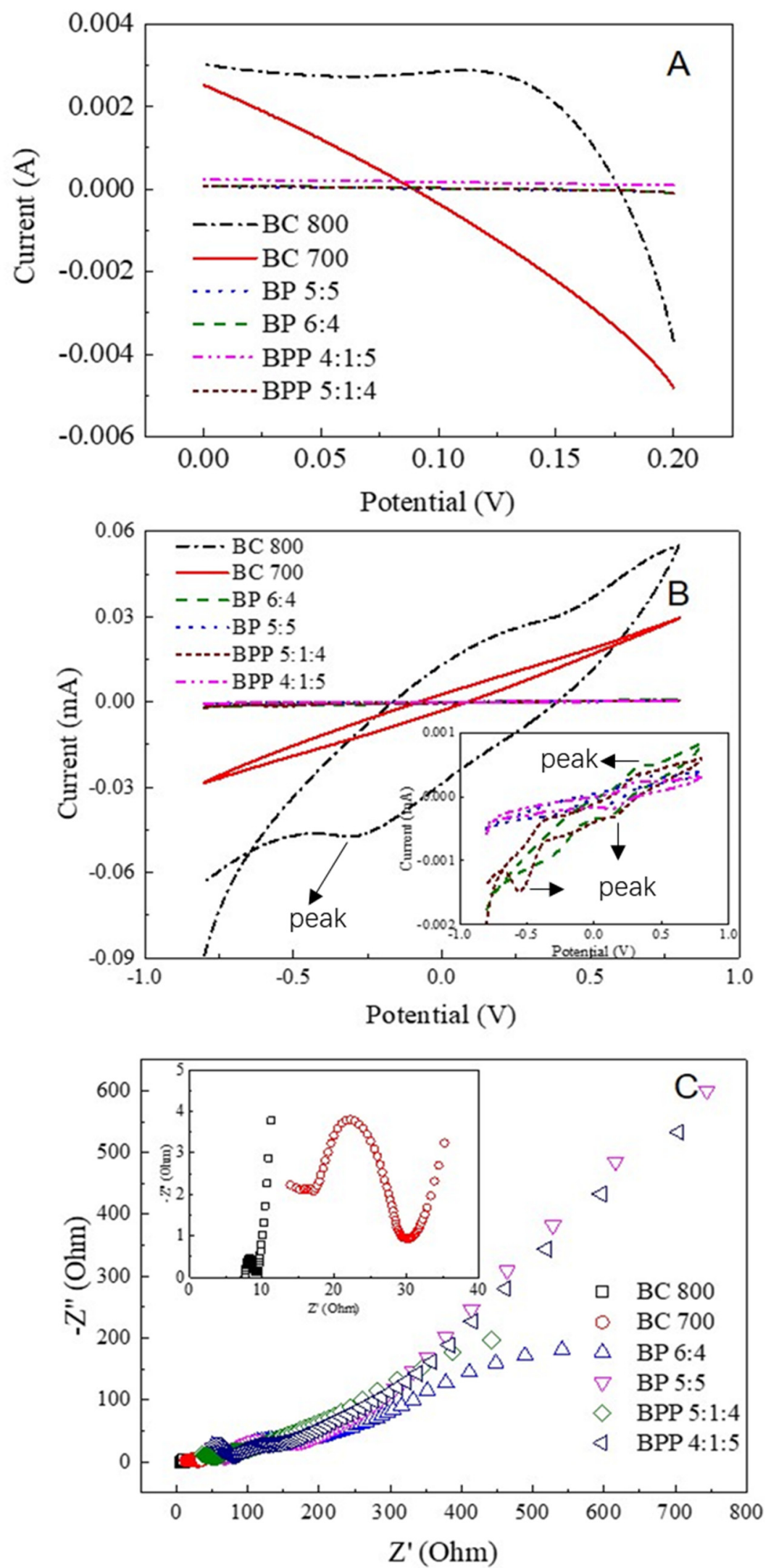

Figure 2. The Linear sweep voltammetry, Cyclic voltammetry, and Electrochemical impedance spectroscopy test results of six biochar-based electrode materials (A) Linear sweep voltammetry curves, (B) Cyclic voltammetry curves, (C) Electrochemical impedance spectroscopy curves. 
The Cyclic voltammetry (CV) curves of six materials are shown in Figure 2B. The CV curves of BC 800 and BC 700 were steeper than other materials. This is consistent with the results of LSV analysis. With the increasing of pyrolysis temperature (from 500 to $900{ }^{\circ} \mathrm{C}$ ), the $\mathrm{CV}$ curves became steeper, indicating that the electrode has a smaller resistance, according to Reference [36]. No steep redox peak was observed in the CV curve of BC 700 and a pair of weak redox peaks were shown in the curve of BC 800. The inset in Figure $2 \mathrm{~B}$ shows $\mathrm{CV}$ curves of $\mathrm{BP}$ and $\mathrm{BPP}$, and small redox peaks could be observed. The peak height of BPP 5:1:4 is higher than that of BPP 4:1:5. The Electrochemical impedance spectroscopy (EIS) test results of six materials are listed in Figure 2C. According to the intersection of the EIS curve and X-axis, the resistances of electrodes could be inferred. The resistances of BC 700 and BC 800 were about 7 and $15 \Omega$, the values of BP $6: 4$ and BP 5:5 were about 56 and $60 \Omega$, and the resistances of BPP 5:1:4 and BPP 4:1:5 were about 38 and $60 \Omega$. Compared with BC 700, the resistance of BC 800 was smaller from the inset image, which was consistent with the $C V$ results. The resistances of $B C 800$ and $B C 700$ were significantly smaller than the other four materials, which showed that the addition of polymer materials in the second step affected the electrochemical properties of these four materials. However, compared to another study, the resistances of pure biochar electrodes measured by the EIS test are slightly higher [37]. The reason may be that the biochar was not activated by $\mathrm{KOH}$ in this study. One-step molding biochar BC 800 and BC 700 may have better electrochemical performance, and these electrodes should be further tested in sediment microbial electrochemical reactors.

\subsection{Performance of Sediment Microbial Electrochemical Reactors with Different Biochar-Based Materials as the Cathodes}

The results of voltage generation of biochar-based materials as cathodes are shown in Figure $3 \mathrm{~A}$. After carbon felts were replaced by biochar-based cathodes, the voltage of the BC 800 reactor increased to $105 \mathrm{mV}$, from $75 \mathrm{mV}$, and the voltage of the BC 700 reactor increased from 70 to $100 \mathrm{mV}$. The results showed that BC 800 and BC 700 can improve the electricity generation performance of sediment microbial electrochemical systems compared with the carbon felt cathode, and these two materials have similar ability to improve the electricity generation $(30 \mathrm{mV})$. The voltage of sediment microbial electrochemical systems with BP 5:5 cathode material decreased from 78 to $60 \mathrm{mV}$, and the voltage of sediment microbial fuel cell (SMFCs) with BP 6:4 cathode material decreased from 75 to $55 \mathrm{mV}$. The addition of polyethylene decreased the conductivity of electrodes and reduced the voltage outputs. The stable voltage of BPP 5:1:4 increased from 85 to $110 \mathrm{mV}$, but the stable voltage of BPP 4:1:5 decreased from 85 to $35 \mathrm{mV}$. It is inferred that the better performance of BPP 5:1:4 compared with BPP 4:1:5 was due to the changes in composition ratio of biochar-based material. BPP 4:1:5 had worse electrical performance than carbon felt, which may be caused by the higher content of hot melt adhesive. These results showed that BC 800, BC 700, and BPP 5:1:4 cathodes have better voltage generation performance.

Polarization curves and power density curves were shown in Figure 3. The power densities were significantly improved at every external resistance after the carbon felt cathodes were replaced with $\mathrm{BC} 800$ and $\mathrm{BC} 700$. The maximum voltage of reactor 1 (BC 800) increased from 75 to $105 \mathrm{mV}$, and the maximum voltage of reactor 2 (BC 700) increased from 70 to $100 \mathrm{mV}$. The current density of the reactors increased by 3.6 times, to $110 \pm 5 \mathrm{~mA} / \mathrm{m}^{2}$. The maximum power density of reactor 1 (BC 800) increased from $1.68 \pm 0.02$ to $9.15 \pm 0.02 \mathrm{~mW} / \mathrm{m}^{2}$, and the maximum power density of reactor 2 (BC 700) increased from $1.45 \pm 0.1$ to $7.4 \pm 0.02 \mathrm{~mW} / \mathrm{m}^{2}$. It showed that the reactors with pure biochar cathode material had small internal resistance and much better performance than carbon felt in reactors. When carbon felt was used in reactor 3 , the voltage of polarization curves decreased from 165 to $10 \mathrm{mV}$ with the change of external resistance, and the current density increased from 2.5 to $32 \mathrm{~mA} / \mathrm{m}^{2}$. The maximum output power density of reactor 3 decreased from $1.75 \pm 0.01$ to $0.6 \pm 0.01 \mathrm{~mW} / \mathrm{m}^{2}$ after BP 5:5 replaced carbon felt, which might be due to the low content of biochar in BP 5:5. After BP 6:4 was replaced in reactor 4 , the voltage range was almost unchanged, but the current density increased from 7.5 to 
$33 \mathrm{~mA} / \mathrm{m}^{2}$. The maximum power density increased from $1.25 \pm 0.01$ to $1.56 \pm 0.01 \mathrm{~mW} / \mathrm{m}^{2}$. When carbon felt was used in reactors 5 and 6 , the polarization curves were similar. After the cathode material was replaced, the voltage range of the polarization curve of reactor 5 (BPP 5:1:4) increased to $190 \mathrm{mV}$, and the current density increased to $70 \mathrm{~mA} / \mathrm{m}^{2}$. The maximum power density of the BPP 5:1:4 reactor increased to $5.25 \pm 0.1 \mathrm{~mW} / \mathrm{m}^{2}$, which was more than two times the original power. However, the reactor with the BPP 4:1:5 cathode only had a power density of about $1 \mathrm{~mW} / \mathrm{m}^{2}$. The voltage of the polarization curve of reactor 6 decreased from 140 to $0 \mathrm{mV}$. BPP 5:1:4 had much better performance than BPP 4:1:5 as the cathode material of sediment microbial electrochemical systems.
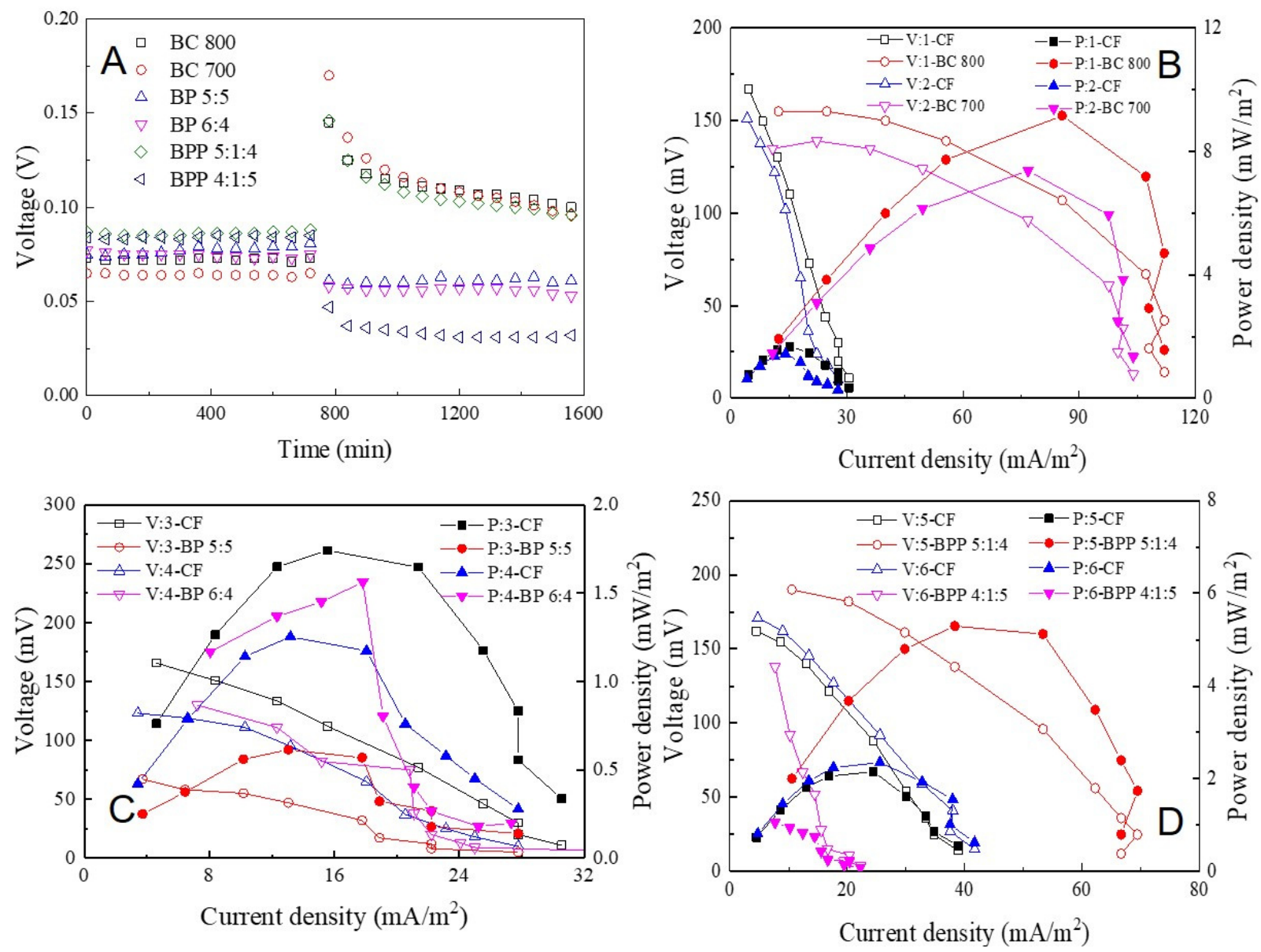

Figure 3. (A-D) The performance of the electricity of sediment microbial fuel cell with different biochar-based materials as the cathodes.

The results showed that BC 800, BC 700, and BPP 5:1:4 had better performance compared with carbon felt, and they had the potential to replace traditional electrode materials. Meanwhile, BC 800, BP 6:4, and BPP 5:1:4 had better performance compared with another electrode obtained by the same preparation method. These results obtained in reactors were consistent with the electrochemical analysis. In particular, BC 800 has the best performance of all six kinds of biochar-based cathodes, and the one-step preparation method was very easy to operate. The improvement degree of BC 800 relative to carbon felt was similar to a previous study, in which BC 900 electrode was used [36]. In another study, the maximum power density of the biochar cathode reached $72 \mathrm{~mW} / \mathrm{m}^{2}$ [26]. The power density was much higher than the value of this research because these two cathode structures were totally different. Air cathodes were one of the most popular cathodes, and superior performance was usually accompanied by complex preparation methods. The one-step molding preparation method used in this study was easy to operate and 
no additional binder was needed. The electrode appearance could remain intact during the research. A feasible method for the one-step molding preparation of biochar-based electrode materials using non-woody plants was developed in the research, and it may be further explored in other microbial electrochemical systems.

\section{Materials and Methods}

\subsection{Biochar Electrodes Preparation}

Biochar electrodes were prepared using Phragmites australis as the precursor material. The preparation process is shown in Figure 4. After the leaves were removed, the reed stalk was cleaned and kept in the $75^{\circ} \mathrm{C}$ oven for $12 \mathrm{~h}$. Then, the reed was crushed and sieved using a 200 mesh strainer. A certain quality of reed powder was put into a heat-resistant corundum mold $(60.0 \times 30.0 \times 9.0 \mathrm{~mm})$ and placed in the furnace and it was preheated at $100{ }^{\circ} \mathrm{C}$ for $20 \mathrm{~min}$ under the protection of nitrogen, then the furnace temperature was further increased to the target pyrolysis temperature $\left(400,500,600,700\right.$, and $\left.800{ }^{\circ} \mathrm{C}\right)$ at the rate of $10{ }^{\circ} \mathrm{C} / \mathrm{min}$ and heated for $2 \mathrm{~h}$. The production was denoted as $\mathrm{BC}$ after cooling. The four other biochar-based materials had a second manufacturing process. BC 700 (target heat temperature was $700{ }^{\circ} \mathrm{C}$ ) was crushed and sieved using a 100-mesh strainer, and the biochar powder and polyethylene were mixed with a mass ratio of 5:5 or 6:4, then the mixture was heated in the furnace from room temperature to $200{ }^{\circ} \mathrm{C}$ at a rate of $10{ }^{\circ} \mathrm{C} / \mathrm{min}$. The reason for choosing this temperature is that polyethylene as a binder will decompose at too-high temperature. The heat lasted for $1.5 \mathrm{~h}$ and the production was cooled to room temperature, and BP 5:5 and BP 6:4 were obtained. The samples of BPP 5:1:4 and BPP 4:1:5 could be obtained similarly to the procedures mentioned above, while the BC 700, polyaniline, and hot-melt adhesive were mixed with the mass ratio of 5:1:4 or 4:1:5.
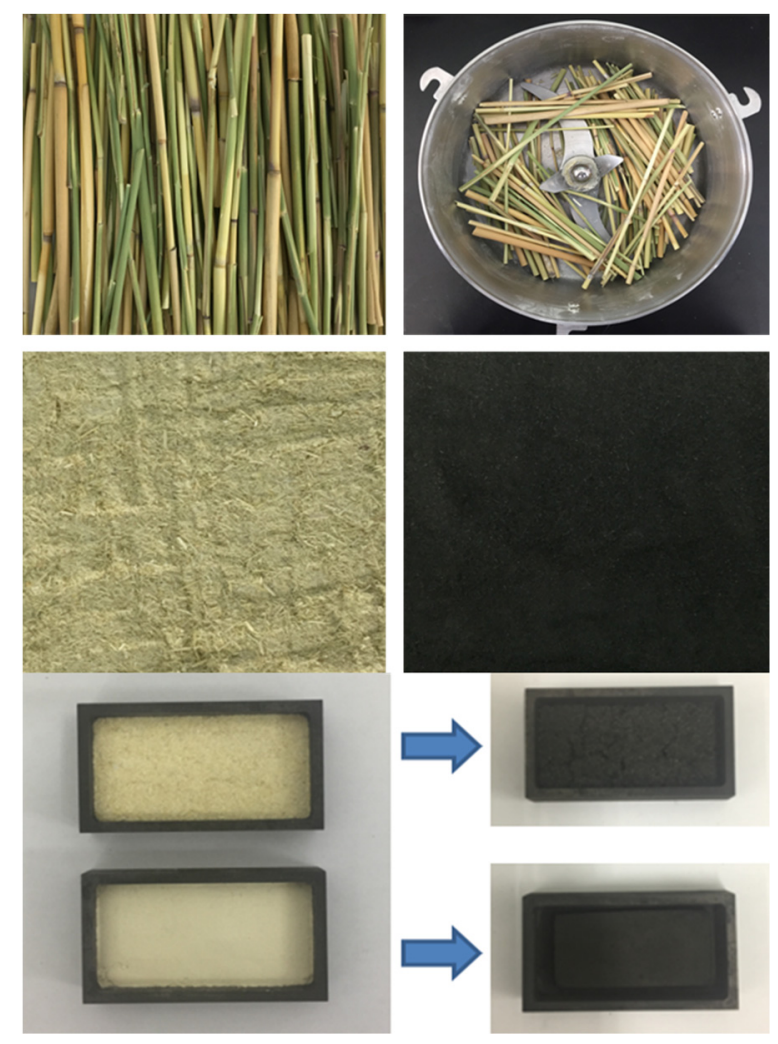

Figure 4. Biochar electrodes' preparation schematic diagram.

\subsection{Determination of Physical and Electrochemical Properties of Materials}

The basic physical indexes mainly include the length, width, thickness, surface roughness, burning loss rate, and resistance of materials. The physical properties of 
materials were determined by caliper (UT61, Dongguan, China) and multimeter (EVERPOWER557115, Shenzhen, China). The morphology of the materials was analyzed by ultra-high-resolution field emission scanning electron microscopy (Nova nanosem 450 type, Hillsboro, America). The electrochemical performance of the materials was mainly tested on the electrochemical workstation (CHI760D, Shanghai, China). All electrochemical tests were performed in a $1 \mathrm{mM}$ potassium ferricyanide solution containing $0.1 \mathrm{M} \mathrm{KCl}$. Cyclic voltammetry $(\mathrm{CV})$ was performed from -0.8 to $0.8 \mathrm{~V}$ at a scan rate of $20 \mathrm{mV} / \mathrm{s}$. EIS was operated over the frequency range of $100 \mathrm{kHz}$ to $0.01 \mathrm{~Hz}$ at an amplitude of $0.007 \mathrm{~V}$.

\subsection{Construction and Operation of Sediment Microbial Electrochemical Reactors}

For a schematic diagram of sediment microbial electrochemical reactors, the interested reader can refer to Reference [38]. Six graphite plates $(60 \times 60 \times 5 \mathrm{~mm})$ were selected as the anode materials of sediment microbial electrochemical reactors $(\Phi 90 \mathrm{~mm}, 500 \mathrm{~mL})$. The graphite plates were polished with sandpaper and heated at $450{ }^{\circ} \mathrm{C}$ for $30 \mathrm{~min}$. Marine mud was collected from the lower part of the mud-water interface, and the sampling site was in Bohai Bay $\left(40^{\circ} 40^{\prime} 15^{\prime \prime} \mathrm{N}, 122^{\circ} 9^{\prime} 42^{\prime \prime} \mathrm{E}\right)$. After pretreatment, the graphite plate anodes were placed horizontally at the center of $300 \mathrm{~mL}$ of marine mud. Carbon felt or the six biochar-based materials mentioned above were used as the cathode. Every cathode electrode (carbon felt in the early stage, replaced by biochar electrodes in the later stage) was fixed with two pieces of titanium mesh and the sandwich structure cathode was placed at the surface of seawater. Anode and cathode were connected with a $1000 \Omega$ resistance. The real-time output voltage was recorded by a personal computer through a data acquisition card (PS2016V, Smacq Technologies, China).

\section{Conclusions}

In this study, biochar molding electrodes by reed were developed. Their basic physical properties and electrochemical properties were characterized, then selected biochar-based electrode materials were used as the cathode of sediment microbial electrochemical reactors to determine the application potential of biochar-based materials. Stable molding materials can be obtained by three preparation methods: one-step molding preparation of pure biochar, two-step molding preparation of biochar/polyethylene composite, and two-step molding preparation of biochar/polyaniline/hot-melt adhesive composite. In order to obtain better one-step molding biochar, it is necessary to select a suitable sieve to treat reed powder. Among the six materials, the BC 800 electrode had the best performance in the sediment microbial electrochemical system, and it was a litter higher compared with BC 700. There was no significant improvement in the reactor using BP 5:5 and BP 6:4 compared with carbon felt. The BPP 5:1:4 and BPP 4:1:5 prepared by the same method have different performance. BPP 5:1:4 increased the power generation, while BPP 4:1:5 inhibited the power generation performance of the reactor. The one-step molding biochar cathode had excellent performance in microbial electrochemical reactors. This one-step biochar molding method is convenient and has a wide range of raw materials, which have the potential to be used in microbial electrochemical systems.

Author Contributions: Conceptualization, K.Y.; data curation, C.G.; writing-original draft preparation, Z.Z.; writing-review and editing, Q.Y.; supervision, Q.Y. All authors have read and agreed to the published version of the manuscript.

Funding: This research was funded by the National Natural Science Foundation of China (51708087).

Conflicts of Interest: The authors declare that the research was conducted in the absence of any commercial or financial relationships that could be construed as a potential conflict of interest.

\section{References}

1. Watanabe, K. Recent Developments in Microbial Fuel Cell Technologies for Sustainable Bioenergy. J. Biosci. Bioeng. 2008, 106, 528-536. [CrossRef] 
2. Moon, H.; Chang, I.S.; Kim, B.H. Continuous electricity production from artificial wastewater using a mediator-less microbial fuel cell. Bioresour. Technol. 2006, 97, 621-627. [CrossRef]

3. You, S.; Zhao, Q.; Zhang, J.; Jiang, J.; Wan, C.; Du, M.; Zhao, S. A graphite-granule membrane-less tubular air-cathode microbial fuel cell for power generation under continuously operational conditions. J. Power Sources 2007, 173, 172-177. [CrossRef]

4. Jiang, D.; Li, B. Granular activated carbon single-chamber microbial fuel cells (GAC-SCMFCs): A design suitable for large-scale wastewater treatment processes. Biochem. Eng. J. 2009, 47, 31-37. [CrossRef]

5. Sohi, S.P. Agriculture. Carbon storage with benefits. Science 2012, 338, 1034-1035. [CrossRef]

6. Maddox, N. The promise [and uncertainties] of Biochar. CSA News Mag. 2013, 58, 4-9. [CrossRef]

7. Lehmann, J.; Gaunt, J.; Rondon, M. Bio-char Sequestration in Terrestrial Ecosystems-A Review. Mitig. Adapt. Strateg. Glob. Chang. 2006, 11, 403-427. [CrossRef]

8. Brosse, N.; Dufour, A.; Meng, X.; Sun, Q.; Ragauskas, A. Miscanthus: A fast-growing crop for biofuels and chemicals production. Biofuels Bioprod. Biorefining 2012, 6, 580-598. [CrossRef]

9. Kookana, R.S.; Sarmah, A.K.; Zwieten, L.V.; Krull, E.V.; Singh, B. Biochar Application to Soil: Agronomic and Environmental Benefits and Unintended Consequences. Adv. Agron. 2011, 112, 103-143.

10. Yan, L.; Guo, Y.; Wei, G.; Zhuo, W.; Ma, Y.; Wang, Z. Simultaneous preparation of silica and activated carbon from rice husk ash. J. Clean. Prod. 2012, 32, 204-209.

11. Uchimiya, M.; Wartelle, L.H.; Klasson, K.T.; Fortier, C.A.; Lima, I.M. Influence of Pyrolysis Temperature on Biochar Property and Function as a Heavy Metal Sorbent in Soil. J. Agric. Food Chem. 2011, 59, 2501-2510. [CrossRef]

12. Ahmad, M.; Rajapaksha, A.U.; Lim, J.E.; Zhang, M.; Bolan, N.; Mohan, D.; Vithanage, M.; Lee, S.S.; Ok, Y.S. Biochar as a sorbent for contaminant management in soil and water: A review. Chemosphere 2014, 99, 19-33. [CrossRef]

13. Wu, P.; Cui, P.; Fang, G.; Gao, J.; Zhou, D.; Wang, Y. Sorption mechanism of zinc on reed, lignin, and reed- and lignin-derived biochars: Kinetics, equilibrium, and spectroscopic studies. J. Soils Sediments 2018, 18, 2535-2543. [CrossRef]

14. Liu, X.-J.; Li, M.-F.; Singh, S.K. Manganese-modified lignin biochar as adsorbent for removal of methylene blue. J. Mater. Res. Technol. 2021, 12, 1434-1445. [CrossRef]

15. Spanu, D.; Binda, G.; Dossi, C.; Monticelli, D. Biochar as an alternative sustainable platform for sensing applications: A review. Microchem. J. 2020, 159, 105506. [CrossRef]

16. Mian, M.M.; Liu, G. Recent progress in biochar-supported photocatalysts: Synthesis, role of biochar, and applications. Rsc. Adv. 2018, 8, 14237-14248. [CrossRef]

17. Jiang, J.; Zhang, L.; Wang, X.; Holm, N.; Rajagopalan, K.; Chen, F.; Ma, S. Highly ordered macroporous woody biochar with ultra-high carbon content as supercapacitor electrodes-ScienceDirect. Electrochim. Acta 2013, 113, 481-489. [CrossRef]

18. Kouchachvili, L.; Entchev, E. Ag/Biochar composite for supercapacitor electrodes. Mater. Today Energy 2017, 6, 136-145. [CrossRef]

19. Ayyappan, C.S.; Bhalambaal, V.M.; Kumar, S. Effect of biochar on bio-electrochemical dye degradation and energy production. Bioresour. Technol. 2018, 251, 165-170. [CrossRef]

20. Huggins, T.; Wang, H.; Kearns, J.; Jenkins, P.; Ren, Z.J. Biochar as a sustainable electrode material for electricity production in microbial fuel cells. Bioresour. Technol. 2014, 157, 114-119. [CrossRef]

21. Marzorati, S.; Goglio, A.; Fest-Santini, S.; Mombelli, D.; Villa, F.; Cristiani, P.; Schievano, A. Air-breathing bio-cathodes based on electro-active biochar from pyrolysis of Giant Cane stalks. Int. J. Hydrogen Energy 2019, 44, 4496-4507. [CrossRef]

22. Jin, C.; Nai, J.; Sheng, O.; Yuan, H.; Zhang, W.; Tao, X.; Lou, X.W. Biomass-based materials for green lithium secondary batteries. Energy Environ. Sci. 2021, 14, 1326-1379. [CrossRef]

23. Caguiat, J.N.; Arpino, G.; Krigstin, S.G.; Kirk, D.W.; Jia, C.Q. Dependence of supercapacitor performance on macro-structure of monolithic biochar electrodes. Biomass Bioenergy 2018, 118, 126-132. [CrossRef]

24. Salimi, P.; Norouzi, O.; Pourhoseini, S.; Bartocci, P.; Tavasoli, A.; Maria, F.D.; Pirbazari, S.M.; Bidini, G.; Fantozzi, F. Magnetic biochar obtained through catalytic pyrolysis of macroalgae: A promising anode material for Li-ion Batteries. Renew. Energy 2019, 140, 704-714. [CrossRef]

25. Thines, K.R.; Abdullah, E.C.; Ruthiraan, M.; Mubarak, N.M.; Tripathi, M. A new route of magnetic biochar based polyaniline composites for supercapacitor electrode materials. J. Anal. Appl. Pyrolysis 2016, 121, 240-257. [CrossRef]

26. Chang, H.C.; Gustave, W.; Yuan, Z.F.; Xiao, Y.; Chen, Z. One-step fabrication of binder-free air cathode for microbial fuel cells by using balsa wood biochar. Environ. Technol. Innov. 2020, 18, 100615. [CrossRef]

27. Liu, Z.; Niu, W.; Chu, H.; Zhou, T.; Niu, Z. Effect of the Carbonization Temperature on the Properties of Biochar Produced from the Pyrolysis of Crop Residues. Bioresources 2018, 13, 3429-3446. [CrossRef]

28. Shen, Z.; Hou, D.; Jin, F.; Shi, J.; Fan, X.; Tsang, D.; Alessi, D.S. Effect of production temperature on lead removal mechanisms by rice straw biochars. Sci. Total Environ. 2019, 655, 751-758. [CrossRef]

29. Yang, H.; Yan, R.; Chen, H.; Lee, D.H.; Zheng, C. Characteristics of hemicellulose, cellulose and lignin pyrolysis. Fuel 2007, 86, 1781-1788. [CrossRef]

30. Khajavi-Shojaei, S.; Moezzi, A.; Norouzi Masir, M.; Taghavi, M. Characteristics of conocarpus wastes and common reed biochars as a predictor of potential environmental and agronomic applications. In Energy Sources, Part A: Recovery, Utilization, and Environmental Effects; Taylor \& Francis Group: Abingdon, UK, 2020; pp. 1-18.

31. Ahmad, M.; Lee, S.S.; Dou, X.; Mohan, D.; Sung, J.K.; Yang, J.E.; Ok, Y.S. Effects of pyrolysis temperature on soybean stover- and peanut shell-derived biochar properties and TCE adsorption in water. Bioresour. Technol. 2012, 118, 536-544. [CrossRef] 
32. Ma, Y.; Yao, D.; Liang, H.; Yin, J.; Xia, Y.; Zuo, K.; Zeng, Y.-P. Ultra-thick wood biochar monoliths with hierarchically porous structure from cotton rose for electrochemical capacitor electrodes. Electrochim. Acta 2020, 352, 136452. [CrossRef]

33. Chen, Y.; Yang, H.; Wang, X.; Zhang, S.; Chen, H. Biomass-based pyrolytic polygeneration system on cotton stalk pyrolysis: Influence of temperature. Bioresour. Technol. 2012, 107, 411-418. [CrossRef]

34. Zhang, Q.; Khan, M.U.; Lin, X.; Cai, H.; Lei, H. Temperature varied biochar as a reinforcing filler for high-density polyethylene composites. Compos. Part B Eng. 2019, 175, 107151. [CrossRef]

35. Das, O.; Bhattacharyya, D.; Hui, D.; Lau, K.-T. Mechanical and flammability characterisations of biochar/polypropylene biocomposites. Compos. Part B Eng. 2016, 106, 120-128. [CrossRef]

36. Wang, B.; Wang, Z.; Jiang, Y.; Tan, G.; Xu, N.; Xu, Y. Enhanced power generation and wastewater treatment in sustainable biochar electrodes based bioelectrochemical system. Bioresour. Technol. 2017, 241, 841-848. [CrossRef]

37. Cuong, D.V.; Wu, P.-C.; Liu, N.-L.; Hou, C.-H. Hierarchical porous carbon derived from activated biochar as an eco-friendly electrode for the electrosorption of inorganic ions. Sep. Purif. Technol. 2020, 242, 116813. [CrossRef]

38. Budihardjo, M.A.; Syafrudin Effendi, A.J.; Hidayat, S.; Purnawan, C.; Lantasi, A.I.D.; Muhammad, F.I.; Ramadan, B.S. Waste valorization using solid-phase microbial fuel cells (SMFCs): Recent trends and status. J. Environ. Manag. 2021, $277,111417$. [CrossRef] 